www.jmscr.igmpublication.org

Impact Factor (SJIF): 6.379

Index Copernicus Value: 71.58

ISSN (e)-2347-176x ISSN (p) 2455-0450

crossrefDOI: https://dx.doi.org/10.18535/jmscr/v6i7.145

Journal Of Medical Science And Clinical Research

\title{
Role of Serum Paraoxonase 1 (PON1) as a Marker of Coronary Heart Disease in Post- Menopausal Women secondary to reduction in serum HDL-C
}

\author{
Authors \\ Dr Shyam Khanderao Kulkarni ${ }^{1}$, Dr Sanjay Shukla ${ }^{2}$, Dr Rahul Kunkulol ${ }^{3}$ \\ Dr Sayyed Asif Umar ${ }^{4}$ \\ Corresponding Author \\ Dr Sanjay Shukla
}

\begin{abstract}
Background: In postmenopausal women, partly in relation to advancing age and partly due to estrogen deficiency, there is increased risk of coronary heart disease (CHD). The oxidation of Low density lipoprotein $(L D L)$ is centrally involved in the initiation of atherosclerosis which ultimately results in CHD. Paraoxonase 1 (PON1) is a major antiatherosclerotic component of High density lipoprotein (HDL) which retards the oxidation of LDL. This study aimed to evaluate the relation between Paraoxonase1 (PON1) activity and post-menopausal status

Methods: On the basis of consecutive recruitment, 80 women between 20 and 76 years old participated in the study. Anthropometric indices (waist circumference, Body mass index) and biochemical parameters (fasting blood glucose, Total cholesterol, Triglyceride, HDL cholesterol and PON1) were measured.

Results: Post-menopausal women in comparison to pre-menopausal women, have significantly low HDL cholesterol and PON1 activity and significantly increased Triglyceride and VLDL cholesterol. PON1 activity was negatively correlated with age, TC, TG, LDL-C. $(r=-0.574,-0.119,-0.226,-0.473$ respectively) and positively correlated with HDL-C $(r=0.368)$. Stepwise multiple regression analysis demonstrated HDL-C and menopausal status as the best determinant for PON1 (R2 $50.320, p<0.05$ )

Conclusion: The use of PON1 measurement may facilitate a simple parameter to evaluate the risk of CHD and to work on its secondary prevention.
\end{abstract}

\section{Introduction}

In India nearly 1.5 million people die of CVD each year. India is suffering from a heavy loss of productive age group as the total burden of CVD is increasing. This is expected that by the year 2030 the loss due to CVD rise to 17.9 million people per year which is 9.4 times greater than that of $\mathrm{USA}^{(1)}$. Atherosclerosis is the leading cause of death in India. Atherosclerosis is a condition affecting the arterial blood vessels where multiple plaques form on the arterial wall that grow in size and eventually reduce the blood flow. When the involved arteries are that of heart, it results in coronary heart disease (CHD). Studies have identified number of risk factors for CHD. The CVD is the leading cause of mortality in women being responsible for 5 lacs deaths per year in USA, which is twice that of deaths due to cancer. It is also found that coronary artery disease is the single largest cause of deaths in postmenopausal women. ${ }^{(2)}$ There is proven gender difference in the pattern of CHD, as the incidee of 
CHD is more in Men than women, due to which for many years it was thought to be a men's disease. The onset of CHD is delayed by some 10-15 years in women compared to men; thus ATP III defines age as a risk factor in women at age 55 , compared to age 45 for $\operatorname{men}^{(3)}$. The reasons for the disparity in ages of onset of CHD between women and men are not fully understood. Nonetheless, patterns of risk factors often differ between men and women; it is also found that CHD is the single largest cause of deaths in postmenopausal women. For example, blood pressure, LDL cholesterol, and triglycerides, rise at an earlier age in men than in women.

HDL-cholesterol levels are on average some 10 $\mathrm{mg} / \mathrm{dl}$ lower in adult men than in women. Since a $10-\mathrm{mg} / \mathrm{dL}$ difference in HDL cholesterol is projected to account for a 20-30 percent difference in CHD event rates over the short term, this difference over the adult lifespan could account for a Significant portion of the gender disparity between men and women. The menopausal transition is proved to be associated with decrease in HDL-C levels ${ }^{(4)}$. Furthermore the menopause in itself a risk factor for atherosclerosis having prevalence of atherogenic lipoprotein profile compared to premenopausal status $^{(5)}$. There is increased prevalence of hypertension and dyslipidemia after menopause. ${ }^{(6)}$ The lipoprotein profile of postmenopausal women is characterized by increased levels of low density lipoprotein (LDL), Lp(a),triglyceride, total cholesterol, and decreased high density lipoprotein (HDL)cholesterol levels. Moreover, triglycerides appear to be an even more powerful and independent risk factor in women than in men. The lipoprotein pattern of postmenopausal women characteristically shows predominance of specific LDL subclass, small dense LDL (sdLDL). It is proved that as age advances the level of serum sdLDL particles also increases in women. ${ }^{(7)} \mathrm{A}$ commonly cited reason for the gender difference is a protective effect of estrogen in women ${ }^{(8,9)}$. Oral estrogens increase HDL cholesterol and decrease LDL cholesterol. Oral estrogens do not mimic the physiologic role of endogenous estrogen, which is released into the systemic rather than the portal circulation ${ }^{(10)}$. The antiatherosclerotic effect of estrogen is probably due to its beneficial influence on lipid metabolism. The estrogen has an antioxidant activity. Thus, after menopause there may be increase in lipid peroxidation and formation of reactive oxygen species. This increased oxidative stress may lead to endothelial injury and increased lipoproteinoxidation including HDL. This ultimately leads to accumulation of oxidized LDL in the subendothelial space leading to atherosclerosis $^{(11)}$. The levels of HDL which was thought to be good cholesterol were proved to decrease after menopause. This may be the reason for increased oxidative stress in postmenopausal women than premenopausal. The decreased HDL may leads to unopposed oxidation of the LDL and increased rate of atherosclerosis. The most crucial anti-atherogenic substance in the body is HDL. The HDL particles play an important role as antioxidants. HDL particles prevent LDL oxidation which is the key step in atherosclerosis. The antioxidant activity of the HDL is mainly due to one enzyme, the Paraoxonase 1 (PON1) ${ }^{(12)}$. The paraoxonases is a family having three distinct PON genes, designated as PON1, PON2 and PON $3^{(13)}$. The PON1 and PON3 are HDL associated enzymes, while PON 2 is expressed in nearly all human tissue. PON2 is not associated with HDL. Among the PON family, PON 1 is the most studied enzyme. The purified serum PON1 has a molecular mass of $43-45 \mathrm{kDa}$ and is a calcium dependent enzyme. The protection offered by PON 1 against atherosclerosis is proved as atherosclerotic lesions reduced in human PON1 transgenic mice ${ }^{(14)}$. There are two major and common polymorphisms found in the PON1 coding region. First glutamine $\rightarrow$ arginine substitution at position 192 i.e. (Q192R), and second leucine $\rightarrow$ methionine substitution at position 55 leading to $(\mathrm{L} 55 \mathrm{M})^{(15)}$. PON1 plays an important role in maintaining low oxidative stress and therefore in the prevention of atherosclerosis ${ }^{(16)}$. 


\section{Materials and Methods}

Total 80 study subjects were enrolled for the study. Permission from the ethics committee of Medical College was taken. Written informed consent was obtained from all the participants Fasting blood sample was collected from the apparently healthy pre-menopausal and postmenopausal women who were selected from the relatives visiting the outpatient department (OPD). Post menopausal women had natural menopause for at least 1 (one) year. Exclusion criteria were women with diabetes, Hypertension, smoking habit, using lipid lowering medicines, hormone therapy and women showing climacteric symptoms. Blood was allowed to clot and the centrifuged for serum separation. Serum Total cholesterol (TC), High Density Lipoprotein cholesterol HDL-C), Triglyceride (TG), was estimated using enzymatic method on smartlab Auto Analyzer (ERBA Mannheim, Germany). Serum PON1 activity was measured using the method described earlier ${ }^{(17)}$. The paraoxonase activity of PON1 was estimated using paraoxon as substrate. The rate of hydrolysis of paraoxon was assessed by measuring the liberation of $p$ nitrophenol at $405 \mathrm{~nm}$. The basal mixture included $2.0 \mathrm{mmol} / \mathrm{L}$ paraoxon and $2.0 \mathrm{mmol} / \mathrm{L}$ of Calcium chloride in $0.1 \mathrm{~mol} / \mathrm{L}$ Tris-HCL buffer ( $\mathrm{pH} \mathrm{8.0)}$. Ten $\mathrm{yL}$ of serum was added to $360 \mathrm{yL}$ of assay mixture. The production of $p$-nitrophenol was constantly monitored at $405 \mathrm{~nm}$ (molar extinction coefficient of 18050) for $5 \mathrm{~min}$. One unit of paraoxonase activity produces $1 \mathrm{nmol}$ of $p$ nitophenol $/ \mathrm{ml}$, and activity was expressed in $\mathrm{U} / \mathrm{L}$ of serum. The intra and interassay coefficient of variation was 3.3 and $4.7 \%$ respectively.

Results obtained were analyzed with MYSTAT (Version 12) software. Data generated were expressed as mean \pm standard deviation. All the parameters were assessed for Normality of distribution by Shapiro-Wilk test. Two sample ttests were applied for comparing means. Regression analysis was used to assess the relationship between parameters. For all statistical tests $\mathrm{p}<0.05$ was considered as the level of significance.

\section{Results}

Postmenopausal women had significantly increased levels of triglycerides than premenopausal women $(167.52 \pm 68.79 \mathrm{v} / \mathrm{s} 118.95$ $\pm 43.41 \mathrm{mg} / \mathrm{dL}), \mathrm{VLDL}-\mathrm{C}(33.85 \pm 14.89 \mathrm{v} / \mathrm{s} 24.30$ $\pm 7.94 \mathrm{mg} / \mathrm{dL})$. Postmenopausal women had a significantly decreased activity in PON1 (116.16 $\pm 7.47 \mathrm{v} / \mathrm{s} 206.55 \pm 69.05)$ and HDL-C (30.92 \pm $7.47 \mathrm{v} / \mathrm{s} 36.67 \pm 7.95)$ when compared with premenopausal women.PON1 activity was negatively correlated with age, TC, TG, LDL-C ( $\mathrm{r}$ $=-0.574,-0.119,-0.226$, and -0.473 respectively) and positively correlated with HDL-C $(r=0.368)$

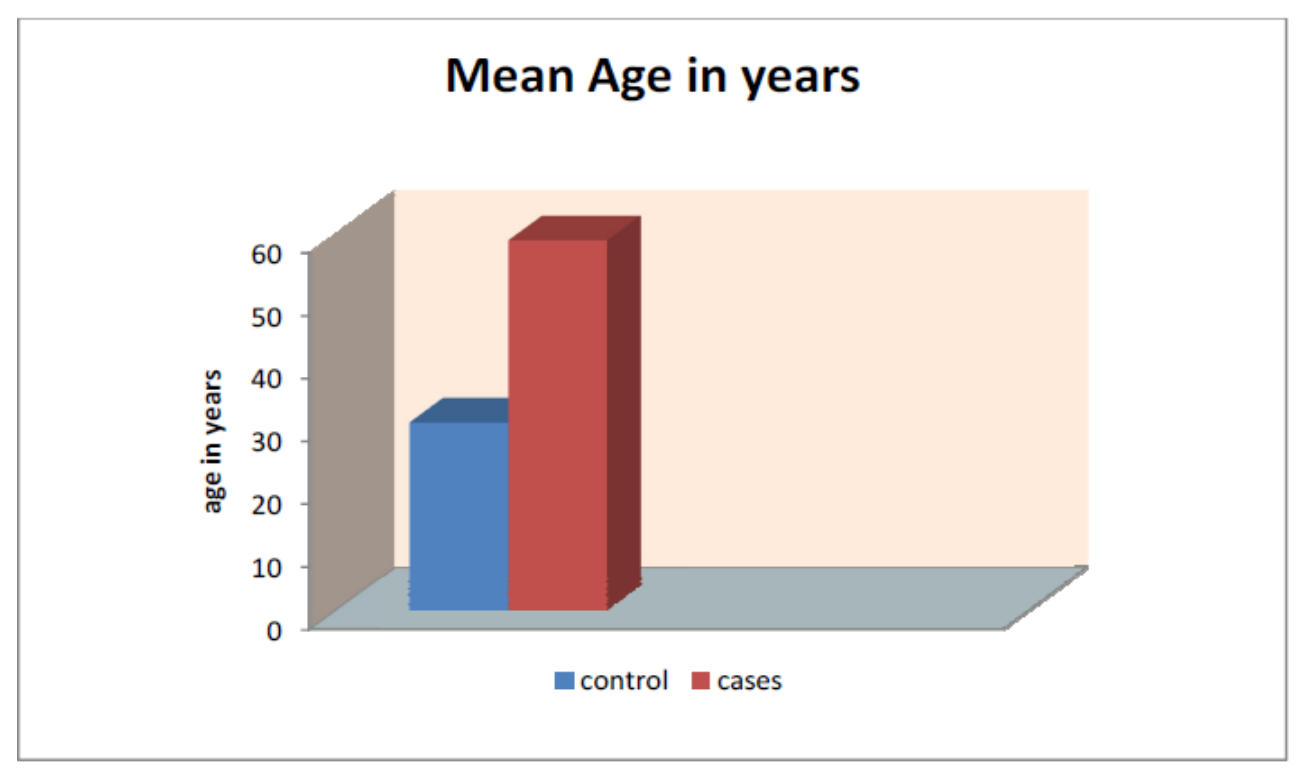


Table 1: Mean age of controls and cases

\begin{tabular}{|c|c|c|}
\hline & Mean age (years) & Standard deviation \\
\hline Controls ( no.40) & 30.12 & 7.20 \\
\hline Cases (no.40) & 59.1 & 10.04 \\
\hline
\end{tabular}

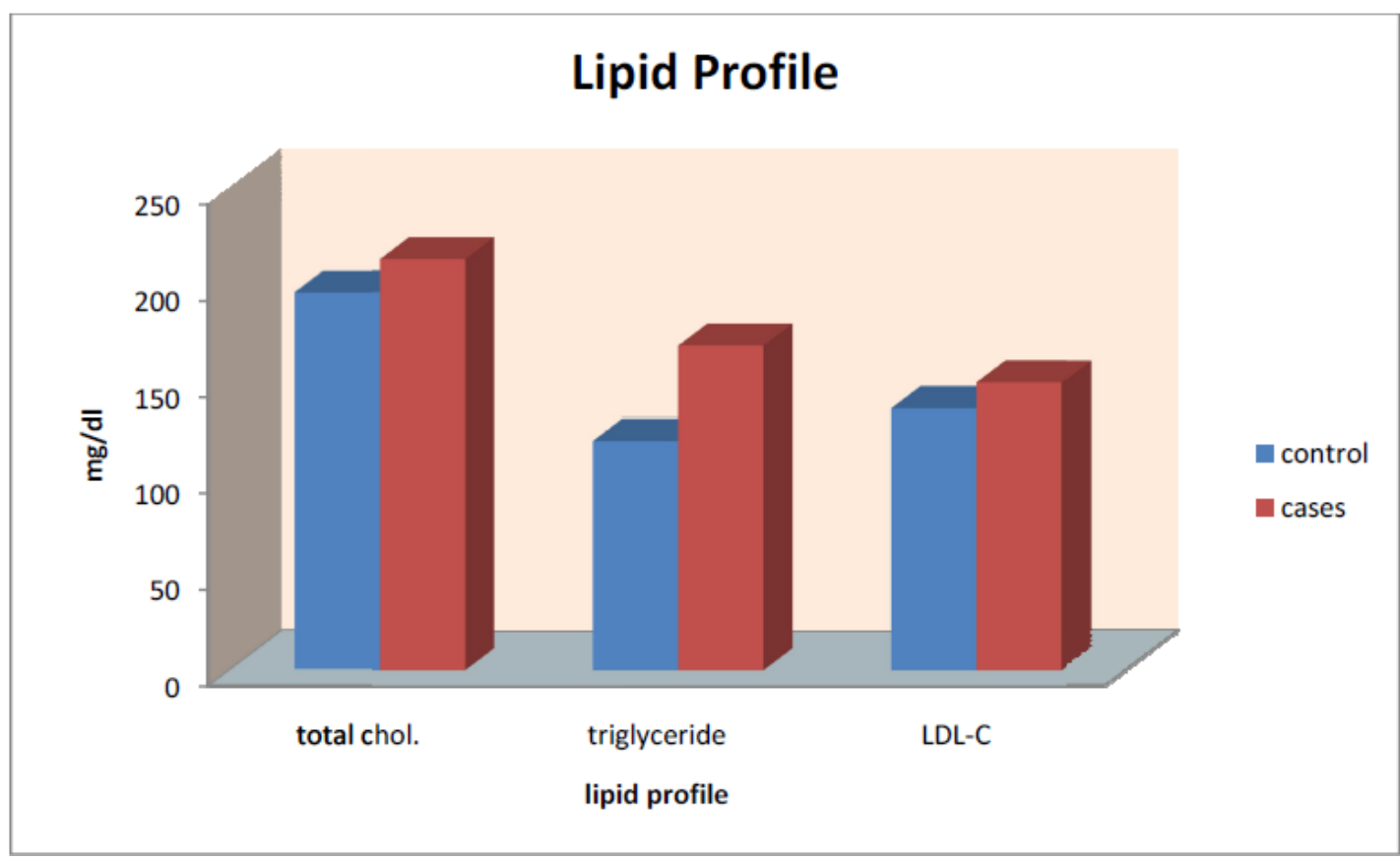

Table 2: Serum Lıpıd protıle in controls and cases.

\begin{tabular}{|c|c|c|}
\hline & $\begin{array}{c}\text { Controls } \\
\mathrm{mg} / \mathrm{dl}(\mathrm{S} . \mathrm{D} .)\end{array}$ & $\begin{array}{c}\text { Cases } \\
\mathrm{mg} / \mathrm{dl} \text { (S.D.) }\end{array}$ \\
\hline Total Cholesterol & $195.35 \pm 36.61$ & $212.37 \pm 48.43$ \\
\hline Triglyceride & $118.95 \pm 43.41$ & $167.52 \pm 68.79^{*}$ \\
\hline LDL-C & $135.12 \pm 34.52$ & $148.55 \pm 40.54$ \\
\hline
\end{tabular}

The Triglyceride levels in cases $(167.52 \pm 68.79)$ are increased significantly $(p$ $<0.05)$ when compared with controls $(118.95 \pm 43.41)$. The serum levels of total cholesterol $(212.37 \pm 48.43$ vs. $195.35 \pm 36.61)$ and LDL-C $(148.55 \pm$ 40.54 vs. $135.12 \pm 34.52$ ) do not show any significant difference in two groups. 


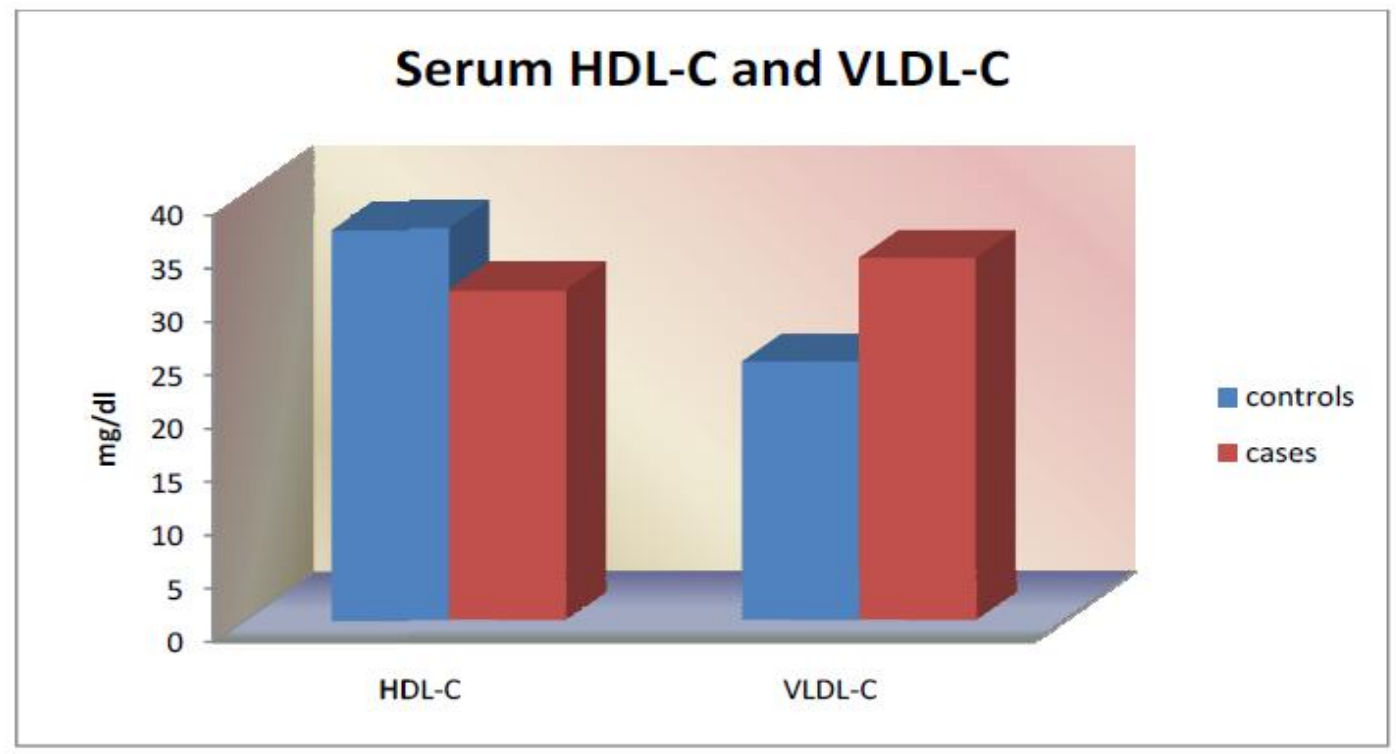

Table 3: Serum HDL-C and VLDL-C in controls and cases.

\begin{tabular}{|c|c|c|c|}
\hline & Controls & Cases & $P$ value \\
\hline HDL-C & $36.67 \pm 7.94$ & $30.92 \pm 7.47$ & $<0.05$ \\
\hline VLDL-C & $24.3 \pm 7.94$ & $33.85 \pm 14.89$ & $<0.05$ \\
\hline
\end{tabular}

The serum HDL-C levels are decreased significantly $(P<0.05)$ in cases $(30.92 \pm 7.47)$ when compared with controls $(36.67 \pm 7.94)$. The VLDL-C levels are increased significantly $(P<0.05)$ in cases $(33.85 \pm 14.89)$ when compared with controls $(24.3 \pm 7.94)$.

\section{Serum PON 1 activity in controls and cases}

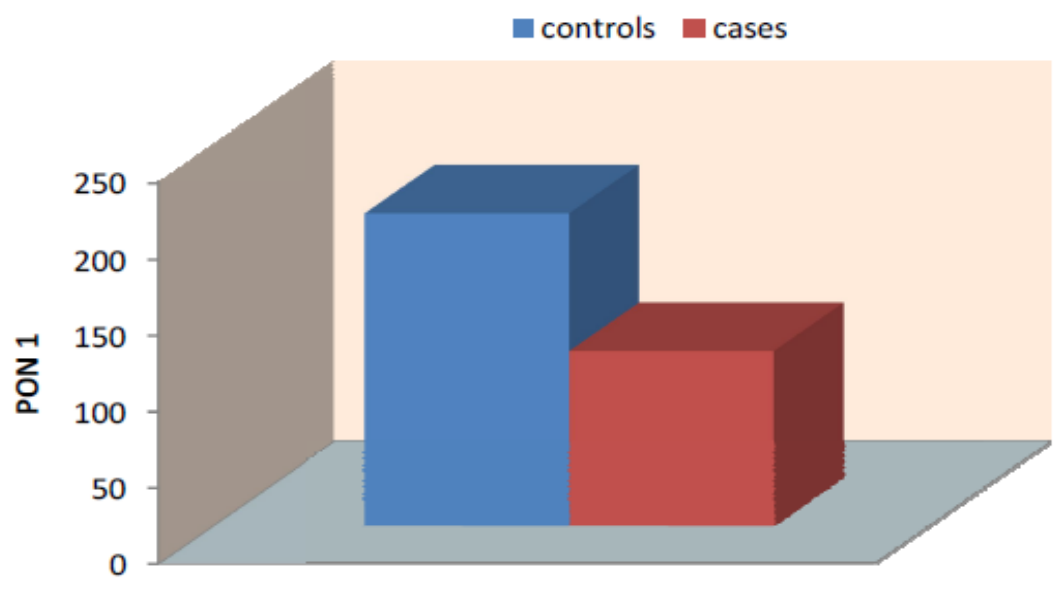


Table 5: Serum Paraoxonase1 activity in controls and cases.

\begin{tabular}{|c|c|c|c|}
\hline & Controls & Controls & P value \\
\hline Paaoxonase 1 (U/L) & $206.55 \pm 69.05$ & $116.16 \pm 76.59$ & $<0.05$ \\
\hline
\end{tabular}

Paraoxonase1 activity in cases (116.16 \pm 76.59$)$ is significantly decreased as compared to controls (206.55 \pm 69.05$)$.

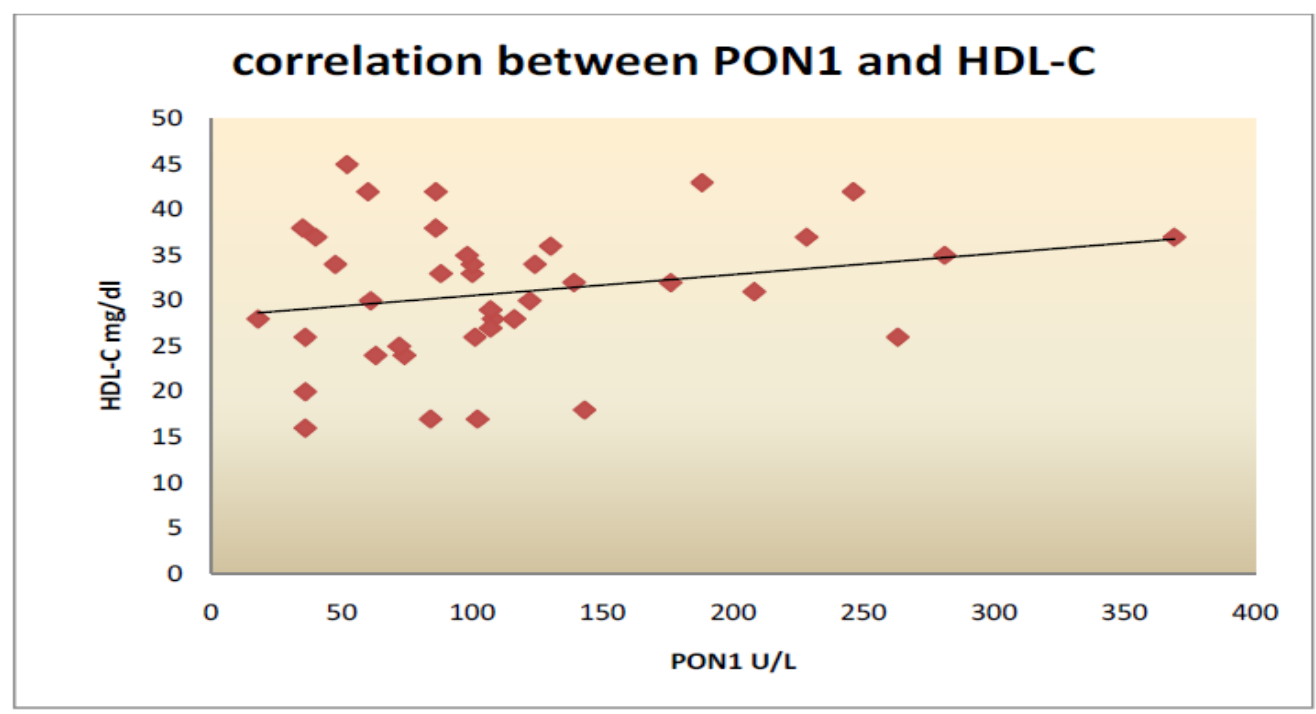

Correlation coefficient, $r=0.237 \quad P<0.05$

There is significant but weak positive correlation between paraoxonase 1 activity and HDL-C levels in cases.

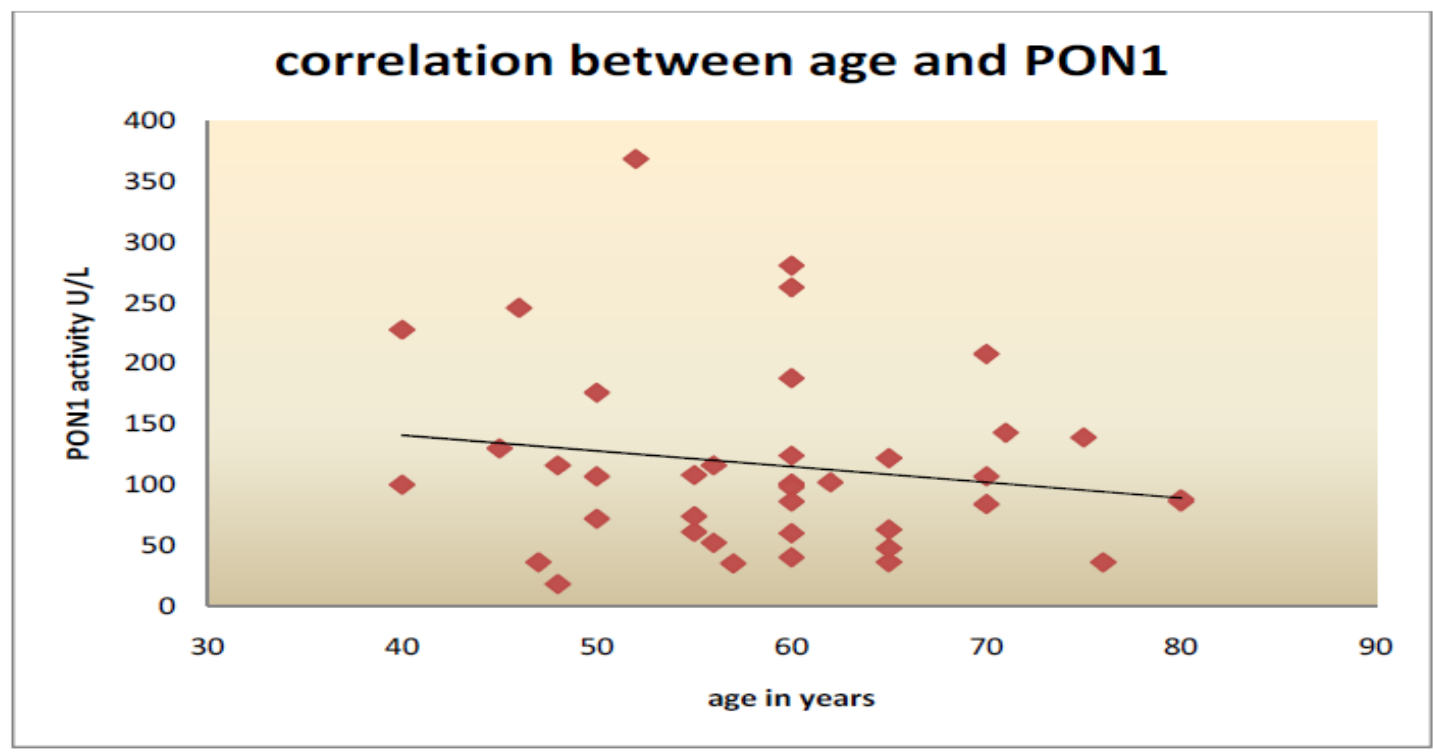

Correlation coefficient, $r=-0.348 ; P<0.001$

The serum paraoxonase1 activity is significantly negatively correlated with the age in cases. 


\section{Discussion}

CVD is the leading cause of mortality in women being responsible for 5 lacs deaths per year in USA, which is twice that of deaths due to cancer. It is also found that coronary artery disease is the single largest cause of deaths in postmenopausal women. ${ }^{(2)}$ Menopause is associated with many hormonal and metabolic changes ${ }^{(18)}$. The alteration in lipoprotein profile is one of them. The dyslipidemia in postmenopausal women is characterized by increased levels of circulating TC, TG, VDLD-C, and LDL-C and decreased HDL-C levels ${ }^{(19)}$. due to these changes postmenopausal women are more prone to develop CHD than the premenopausal. The present study demonstrates significant changes in lipoproteins in healthy postmenopausal women. There is significant increase in triglyceride levels with decreased HDL-C levels. The changes are accompanied by significant decrease in the PON1 activity in the postmenopausal women which can protect both HDL and LDL from oxidation. In the present study, postmenopausal status has emerged as a single factor predicting decreased PON1 activity. These changes represent a net descent of lipoprotein functionality in postmenopausal women, which would contribute to increased risk for CHD. The significantly decreased paraoxonase 1 activity in postmenopausal women $(116.16 \pm 76.59)$ compared to premenopausal (206.55 \pm 69.05) suggest decreased antioxidant defense after menopause. PON1 is an antioxidant enzyme with close association with HDL through apo A1.(20) The circulating levels of HDL may affect the PON1concentration and in turn the activity also. The decreased levels of HDL-C in our study are significantly related to decreased activity of PON1. Our results are very much similar to the findings by Selahattin Kumru et al(21), with decreased activity of PON1 in elderly women compared to younger. As previously discussed the lipoprotein metabolism may be influenced by the oestrogen. The postmenopausal decrease of oestrogen may indirectly affect the PON1 concentration and activity. The postmenopausal decrease in PON1 activity was also seen in the study of Ata Topcuoglu, ${ }^{(23)}$ where the activity get enhanced after the treatment with oestrogen. This finding further support our assumption of oestrogen related decrease in PON1 activity.An age dependency of PON1 is clearly seen in present study, showing strong negative correlation with age $(r=-0.348)$. Ildiko Seres et $\mathrm{al}^{(22)}$ also found the similar correlation in the elderly women. The menopausal transition is associated with an increased oxidative stress ${ }^{(11)}$ In the postmenopausal women, there is increased oxidation of the LDL and HDL. ${ }^{(28)}$ The antioxidant activity is attributed to HDL and oestrogen $^{(24)}$. The HDL particles are the key players in the circulation to inhibit oxidation of LDL. The antioxidant activity of HDL is partly due to $P O N 1^{(25)}$. Thus the reduction in the antioxidant potential of PON1 might also influence the susceptibility of LDL and HDL to oxidation and also the antioxidant properties of HDL. The age related decrease in HDL-C may lead to increased LDL and HDL oxidation. The oxidized LDL appears to inactivate PON1 through interactions between the enzyme- free sulfhydril group and oxidized lipids which are formed during LDL oxidation ${ }^{(26)}$. The oestrogen has an antioxidant activity, which act with other antioxidants protecting tissue from oxidative damage. ${ }^{(25)}$ Ata Topcuoglu et $\mathrm{al}^{(23)}$ shown the increased oxidative stress in the form of increased malondialdehyde (MDA), and oxLDL after the menopause. These changes found to be reversed after exogenously given oestrogen. In previous studies $^{(21)}$, there was significant negative correlation between PON1 and MDA in the postmenopausal women suggesting oxidative imbalance with decreased antioxidants and increased activity of oxidants during menopausal transition. ${ }^{(26)}$ The menopausal transition is also associated with an increased oxidativse stress ${ }^{(27)}$. In postmenopausal women, there is increased oxidation of $\mathrm{LDL}$ and $\mathrm{HDL}^{(23)}$. Antioxidant activity is attributed to HDL. Antioxidant activity of HDL is partly due to PON $1^{(25)}$. Thus, 
postmenopausal reduction in the activity of PON1 might also influence the susceptibility of LDL and HDL to oxidation. Oxidized LDL appears to inactivate PON1 through interactions Between the enzyme- free sulfhydryl group and oxidized lipids, which are formed during LDL oxidation ${ }^{(28)}$. Decreased activity of PON1 in postmenopausal women or women with surgical menopause can be reversed with estrogen therapy ${ }^{(21)}$. Recently, climacteric symptoms are also shown to be associated with risk factors for cardiovascular diseases and increased oxidative stress in perimenopausal women or early after menopause (29). However, the present study did not include women with climacteric symptoms. Results of the present study indicate that the lipoprotein changes in the form of decreased HDL and decreased PON1 may be risk factors for coronary artery diseases in postmenopausal women. The present study is an observational study, which has major strengths including that it is contemplated to be the first study in postmenopausal women determine the effects of menopause over the serum concentrations of HDL and PON1. There are several caveats to the present study. We did not estimate the serum estrogen levels which restricts our conclusion. The actual arterial changes were not assessed by us. Multicentric studies with larger sample size may be useful to know the actual Role of Serum Paraoxonase 1 (PON1) as a Marker of Coronary Heart Disease in Post-Menopausal Women secondary to reduction in serum HDL-

\section{References}

1. Park's Textbook of PSM, 20th edition, K Park, Atherosclerosis, noncommunicable diseases, page 316-317. Bhanot publication.

2. Sybil L Crawford, C B Johannes. The epidemiology of cardiovascular diseases in postmenopausal women. J. Clin. Endocrinol. Metab.1999;84: 1803-18066) Tremollieres F A, Pouilles J M, cauneille C, Ribot C. Coronary heart disease risk factors and menopause: a study in 1684 French women. Atherosclerosis, 1999; 142: 415- 423.

3. Third Report of the National Cholesterol Education Program (NCEP) Expert Panel on Detection, Evaluation, and Treatment of High Blood Cholesterol in Adults (adult Treatment Panel III) Final Report. Circulation 2002;106:3153.

4. Gaspard UJ, Gottal JM, van den Brûle F a. Postmenopausal changes of lipid and glucose metabolism: a review of their main aspects. Maturitas. 1995;21(95):171-8.

5. Goh VHH, Tong TYY, Mok HPP, Said B. Differential impact of aging and gender on lipid and lipoprotein profiles in a cohort of healthy Chinese Singaporeans. Asian J Androl. 2007;9(6):787-94.

6. Tremollieres F A, Pouilles J M, cauneille C, Ribot C. Coronary heart disease risk factors and menopause: a study in 1684 French women. Atherosclerosis, 1999; 142: 415- 423.

7. Selby J V, Austin M A,Newman B, Zhang $\mathrm{D}$ et al. LDL subclassphenotype and the insulin resistance syndrome in women.Circulation 1993; 88: 381-387.

8. J George fodor, rayka Tzerovska. Coronary heart disease: is gender important? The $J$ of men health and gender; 2004;1(1):32-37

9. Yen Y Tan, et al, gender differences in risk factors for coronary heart disease. Maturitas 2010;65:149-160

10. Yichuan Wen et al, Effect of menopause on low density lipoprotein oxidation:is estrogen an important determinant?Maturitas 2000;34:233-8

11. Valeria zago, Silvia S. Brites F. Berg G et al. Impaired HDL antioxidant activity in healthy postmenopausal women. Atherosclerosis, 2004; 177: 203-210.

12. Watson a D, Berliner J a, Hama SY, La Du BN, Faull KF, Fogelman a M, et al. Protective effect of high density 
lipoprotein associated paraoxonase.

Inhibition of the biological activity of minimally oxidized low density lipoprotein. J Clin Invest. 1995;96(December):2882-91.

13. Primo-Parmo SL, Sorenson RC, Teiber J, $\mathrm{La} \mathrm{Du}$ BN. The human serum paraoxonase/arylesterase gene (PON1) is one member of a multigene family. Genomics. 1996;33(33):498-507.

14. Tward a. Decreased Atherosclerotic Lesion Formation in Human Serum Paraoxonase Transgenic Mice. Circulation [Internet]. 2002;106:484-90. Available from:

http://circ.ahajournals.org/cgi/doi/10.1161/ 01.CIR.0000023623.87083.4F

15. Adkins S, Gan KN, Modyt M, Dut BN La. Molecular Basis for the Polymorphic Forms of Human Serum Paraoxonase/Arylesterase: Glutamine or Arginine at Position 191 , for the Respective A or B Allozymes. Am J Hum Genet. 1993;52:598-608.

16. Mackness M, Mackness B, Durrington PN. Paraoxonase and coronary heart disease. Atheroscler Suppl [Internet]. 2002;3:4955. Available from: http://www.ncbi.nlm.nih.gov/pubmed/153 13350

17. Eckerson HW, Romson J, Wyte C, La Du $\mathrm{BN}$. The human serum paraoxonase polymorphism: identification of phenotypes by their response to salts. Am J Hum Genet. 1983;35:214-27.

18. De Aloysio D, Gambacciani M, Meschia M, Pansini F, Modena AB, Bolis PF, et al. The effect of menopause on blood lipid and lipoprotein levels. Atherosclerosis. 1999;147:147-53.

19. Schaefer EJ, Lamon-Fava S, Cohn SD, Schaefer MM, Ordovas JM, Castelli WP, et al. Effects of age, gender, and menopausal status on plasma low density lipoprotein cholesterol and apolipoprotein
B levels in the Framingham Offspring Study. J Lipid Res [Internet]. 1994; 35:779-92. Available from: http://www.ncbi.nlm.nih.gov/pubmed/807 1601

20. Michal Harel, Amir Aharoni, Leonid Gaidukov, Boris Brumshtein, OlgaKhersonsky, Ran Meged et al. Structure and evolution of the serumparaoxonase family of detoxifying and antiatherosclerotic enzymes.Nature structural and molecular biology. 2004;11: 412-419

21. Kumru S, Aydin S, Aras A, Gursu M, Gulcu F. Effects of surgicalmenopause and oestrogen replacement therapy on serumparaoxonase activity and plasma malondialdehyde concentration.

22. Seres I, Paragh G, Deschene E, Fulop T, Khalil A. Study of factorsinfluencing the decreased HDL associated PON1 activity with aging.Experimental Gerontology 2004; 39: 59-66.

23. Topcuoglu A, Uzun H, Aydin S, Kahraman N, Vehid S, Zeybek G. etal. The effect of hormone replacement therapy on oxidized low densitylipoproteinlevels and paraoxonase activity in postmenopausalwomen. Tohoku J. Exp. Med. 2005; 205:79-86.

24. Matthias Barton, Mark M Kockx. Estrogen and apoptosis inatherosclerosis. International Congress series, 2002; 1229: 81-93

25. Michael I Mackness and Colin H Walker. Multiple forms of sheepserum Aesterase activity associated with the high density lipoprotein.Biochem J. 1988; 250: 539545.

26. Aviram M, Scott B, Robert S, Charles B, Roger N, Rosenblat M.Paraoxonase active site required for protection against LDL oxidationinvolves free sulfhydryl group and is different from that required for itsarylesterase/paraoxonase activities : selective action of humanparaoxonase 
allozymes Q and R. Arterioscler Thromb Vasc Biol1998;18;1617-1624.

27. Zago V, Sanguinetti S, Brites F, Berg G, Verona J, Basilio F, et al. Impaired high density lipoprotein antioxidant activity in healthy postmenopausal women. Atherosclerosis. 2004;177:203-10

28. Hiroshi Yoshida, Reiko Kisugi. Mechanism of LDL oxidation. Clinica Chimica acta, 2010; 411: 1875-1882

29. Cagnacci a, Palma F, Romani C, Xholli a, Bellafronte M, Di Carlo C. Are climacteric complaints associated with risk factors of cardiovascular disease in peri-menopausal women? Gynecol Endocrinol [Internet]. Informa UK Ltd; 2015;31(00):359-62. 